\section{Copyright, academic research and libraries: balancing the rights of stakeholders in the digital age}

\author{
Shalini R. Urs
}

\section{The author}

Shalini R. Urs is Professor and Chairperson, Department of Information and Library Studies, University of Mysore, Manasagangotri, Mysore, India and is also Director, Vidyanidhi Digital Library.

\section{Keywords}

Digital libraries, Copyright law, Intellectual property, Research

\section{Abstract}

Following an overview of the historical context of copyright legislation, this paper discusses copyright within the scholarly communication process and the role of libraries in providing access to copyright materials in the digital age. The argument is made that the balance of "rights" and "exceptions" that has been maintained for 300 years needs to be reconsidered for scholarly communications, such as theses and dissertations, as well as for articles in electronic journals. This type of information is fact-based, often resulting from public funds, and is part of the intellectual heritage of academic institutions, and so is very different to creative works within the entertainment industries.

\section{Electronic access}

The Emerald Research Register for this journal is available at

www.emeraldinsight.com/researchregister

The current issue and full text archive of this journal is available at

www.emeraldinsight.com/0033-0337.htm

\section{Context}

As libraries move from the physical medium to the digital, library staff are increasingly confronted with the challenges of addressing copyright and other intellectual property rights (IPR) issues related to digital information. Copyright has become a hot topic and a vexing issue for all those who have a stake in scholarship and scholarly communication. In the digital world, the very premises and philosophy of copyright are being questioned and voices are being heard reviewing its tenets. What is so different in the digital age that has made it an engaging topic for all the stakeholders in the scholarly communication process? Balancing conflicting "private" and "public" interests is neither easy nor unequivocal. This issue is further accentuated in the world of academic research, where the private and public concepts are very nebulous. The issue of rights ownership transgresses into the realm of hairsplitting issues of creativity, work for hire and other equally contentious matters. In the world of scholarship and intellectual heritage, libraries play a very important role: libraries are the voices for the "public good". But, in the digital millennium, how do we balance often conflicting interests? How are libraries and library services affected? This paper attempts to examine copyright issues and their exceptions, especially in the context of academic research, with a view to highlight the issues that are of concern to libraries, scholarship and to society.

\section{Intellectual property and copyright}

\subsection{The basics}

The World Intellectual Property Organisation (WIPO) of the United Nations defines intellectual property as:

... creations of the mind: inventions, literary and artistic works, and symbols, names, images, and designs used in commerce. Intellectual property is divided into two categories: industrial property, which includes inventions (patents), trademarks, industrial designs, and geographic indications of source; and copyright, which includes literary and artistic works such as novels, poems and plays, films, musical works, artistic works such as drawings, paintings, photographs and sculptures, and architectural designs. Rights related to copyright include those of performing artists in their performances, producers of phonograms in

Received: 12 March 2004

Revised: 5 April 2004

Accepted: 9 April 2004

All the URLs in this paper were checked on 6 April 2004. 
their recordings, and those of broadcasters in their radio and television programs (www.wipo.int/ about-ip/en/).

The challenges of intellectual property issues stem from their very nature - their value increases with use, and the value of intellectual property lies in public use! Unlike other economic goods, market forces that operate in this domain are not purely economic. Knowledge is not of much value if it is not disseminated. The fact that it is not consumed but catalyses the creation of new knowledge compounds the issue further.

The history of copyright can be traced back to 1662, when the concept was developed to protect publishers against piracy following the

technological advances of the day, which enabled cheap and easy printing of books. The world's first copyright legislation was the UK Copyright Act of 1709, sometimes referred to as the Statute of Queen Anne, which passed into law in 1710 and introduced the concepts of the author being the owner of the copyright of the created work and there being a fixed term of protection for published works. In addition, there was a legal obligation for copies of published books in the UK to be deposited in certain libraries, including the university libraries of Cambridge and Oxford.

Copyright tradition has evolved mainly for creating an environment that promotes creativity and knowledge. The forces and incentives that help produce creative or intellectual works are diverse. The antecedent of the Statute of Queen Anne was the Royal patent grants, which offered printers and booksellers monopoly rights to publish books and the like. The original purpose was to exercise central authority to control publishing and generate tax revenue. The Statute of Queen Anne was designed to encourage people to produce creative works, but the UK's House of Lords also viewed these creative works as for the public good, and hence monopoly rights were strictly limited originally to 28 years.

Copyright is concerned with the rights of authors, composers, artists and other creators in their works. Copyright grants them the right, for a limited period of time, to authorise or prohibit certain uses of their works by others. These rights encompass basically two aspects - economic and moral. The main aim of copyright is to provide a stimulus for creativity - ensuring economic returns on the creation and protection from violation of the creation. Moral rights generally cover the right of "paternity" by which authors have the right to claim authorship of their works, ensuring that their names are mentioned in connection with them. It is interesting to note that etymologically the term "author" means "father". The right of integrity is another dimension of the copyright. The spirit behind the concept of copyright is enshrined and exemplified in the United States Constitution, which provides that Congress has the power to "promote the progress of science and useful arts, by securing for limited times to authors and inventors the exclusive right to their respective writings and their discoveries" (Besek, 2003).

Within national territories, copyright protection is provided by national laws. International protection has been provided since 1886 through the International Copyright Act and the Berne Convention (see www.cerebalaw.com/berne.htm), which has over 100 countries as signatories and is managed by WIPO. The Berne Convention provides for a minimum level of copyright protection. The freedom for individual countries to regulate for certain issues, and regulate more than what is provided for in the Berne Convention, has resulted in a variety of different copyright legislations among signatories of the Convention.

Any original work of authorship fixed in a "tangible medium of expression" is automatically copyrighted. The medium can be almost anything - paper, discs, clay, film, sound recording, video, digital data and so on. Originality has never been defined very precisely. However, to qualify as "original" it has to be something that is not copied and has to exhibit a small amount of creativity.

Copyright legislation does not protect ideas and facts - whether scientific, historical, biographical or other happenings of the day. Any facts that an author discovers in the course of research is public domain information, i.e. free for public use.

Copyright is owned by the creators, their assignees, or their employers, and official registration of copyright is unnecessary. Copyright is limited in time - it generally covers the life of the author and a said number of years (varying from country to country). Copyright is in essence a bundle of rights covering the following:

- Rights for reproduction, i.e. exclusive rights to make copies of the work. For the purposes of this right, a copy of any work can be in any form in which the work is fixed and from which it can be perceived, reproduced or communicated either directly or with the help of a machine.

- Rights for modification/adaptation, i.e. exclusive rights to modify and make adaptations and create derivative works. A work in a different medium such as, say, a film as compared to a book, is an adaptation or a derivative.

- $\quad$ Rights for distribution, i.e. the rights distribute the work to the public.

- $\quad$ Rights for public performance, i.e. the right to recite, play, dance, or act with or without the aid of a machine. 
- Rights for public display, i.e. the right to display the work anywhere that is open to the public (anywhere that a substantial number of persons outside the normal circle of a family and social acquaintances are gathered).

Authors and creators are granted certain monopoly rights over their works in order that these assurances of returns on their efforts stimulate the creation of intellectual works. Limits and the exceptions to these rights (as described later) promote the arts and the sciences. Copyright laws also permit transfer of rights to a third party, such as publishers, in order that they can bring the works of the authors/creators to the market.

A sense of balance is implicit in the provisions of copyright. One of the critical principles of copyright policies is to help equalise, leverage, and balance rights. Apart from fair use and doctrine of first sale, another underlying element of copyright has been the "limited time" factor, thus ensuring that eventually all works become "public domain". The Guide to Regional Intellectual Property Laws for Librarians (Baker and McKenzie, 2002), produced under the auspices of CONSAL, helps those working in libraries and knowledge centres in the CONSAL region to understand new and emerging issues in IPR and copyright management.

\subsection{Exceptions to copyright with respect to libraries}

Copyright is not absolute. There are a number of limiting principles and exceptions to the rights. Those principles that are relevant for libraries in the digital age are listed below:

(1) Archiving and copying. Libraries and archives are permitted to make up to three copies of unpublished copyrighted works for the purposes of preservation, security or for deposit for research use in another library or archive. Libraries can also make up to three copies of a published work to replace a work in their collection if it is damaged, deteriorated or lost, or the format of which has become obsolete.

(2) Fair use. What constitutes "fair use" is debatable. However there are certain factors that govern fair use:

- Purpose and character of use, i.e. is it for commercial use or for non-profit educational purposes?

- Nature of the copyrighted work. The fair use principle is generally more lenient for fact-based works than it is for "fanciful" works, and also is broader for published works than it is for unpublished works.

- Amount or proportion of the whole that is to be copied.
- Effect that the use has on market potential or the value of the copyrighted work.

(3) First sale doctrine. The matter of disposition of a particular copy of a copyright is limited by the first sale doctrine, according to which the owner of that particular copy of the work may sell or transfer that copy. Libraries' lending and marketing of used books are governed by the first sale doctrine.

Issues and concerns are complicated by the difficulty of defining what constitutes a "copy" in the digital age. The first copy may be the only copy for which the copyright receives an economic return. The paranoia of the holders of copyright stems from this fear of losing the market and the right to distribute (Giavarra, 1999). There are understandable concerns of users, including those of libraries, regarding loss of their rights as provided for in the above "exceptions".

\section{Scholarly communication, copyright, libraries and preservation of intellectual heritage}

The role that libraries play in the scholarly communication process is shaped by the provisions of the copyright. There are essentially three players:

(1) the creators, who have legal rights;

(2) the publishers, who have legal rights due to transfer; and

(3) the users (individuals and institutions such as libraries and academe), who have legal rights through exceptions and limits.

Authors produce creative and intellectual works while the publishers create a market and distribute and sell the works. The functions of libraries have been well defined over the years - collection, preservation, organisation and dissemination of works of intellectual and artistic content in order to facilitate their use. One of the important distinctions between the roles of other intermediaries and libraries is the preservation function. Historically, libraries, as social and cultural institutions, have the mandate not only to ensure equity of access and availability to the present generation of users, but also have the responsibility of ensuring that access and availability for future users. Libraries acquire, preserve, lend and provide access to works, including those that have lost market viability or are out of print. Often libraries are the only agencies that preserve public domain materials. Libraries are the facilitators that enable users to exercise their rights to access copyrighted as well as public domain works. This system seems to have 
worked fairly successfully for nearly 300 years. The role of libraries in the preservation of digital information sources is discussed later.

\section{Copyright in the digital age: a threat to the cultural ecology?}

What is different in the digital age? Copyright laws are an instrument of balancing the interests of creators and the societal obligations to facilitate the free flow of information. Advances in technology (including "player pianos" in the early 20th century, cable television, computers and the Internet) have demanded a review and reworking of the copyright laws. For 300 years fairly discernible boundaries between the players/ creators and end users/consumers in the scholarly communication process were drawn, and apparently conflicting interests could be fairly gracefully accommodated. But the digitally networked world has threatened this cultural ecology and has dramatically shifted the balance with the ability to download materials, to make any number of perfect copies and distribute these with virtually no extra cost or effort. Creators feel threatened and have become paranoid in view of the threat to their market potential, and so technology is being used to enable copyright holders to exercise enormous restrictions and controls over use. Safeguarding the private and public interests has been reduced to a win or lose situation. The Digital Millennium Copyright Act (DMCA) of 1998 in the US is one such example (see www.copyright.gov/legislation/dmca.pdf) which has endangered the legitimate "fair use" of creative works. Retaining the balance between public and private concerns is the key to addressing the challenge of achieving an equilibrium of intellectual property rights.

The library community has often been the champion of the cause of "public good", and has traditionally been the agency that has offered opportunities for the public to benefit from copyrighted and public domain materials. Therefore it is natural that the library and information professions are concerned that this balance is maintained in the digital environment. Libraries act in the vanguard of maintaining the cultural ecosystem.

\section{Copyright and academic research: issues and arguments}

It is not the digital age alone that is causing imbalances in the ecology of scholarly communication culture. Questions are also being raised regarding the tenets of the system of copyright for a variety of other reasons. The complexities, conflicts and confusions relating to copyright in the domain of scholarship arise from our failure to separate the different categories of intellectual property - one size does not fit all. Grouping all created works under a single folder results in a diverse set of works coming under the umbrella of the same copyright legal system.

Intellectual academic research works and creative/ artistic works clearly meant for commercial purposes are all treated under the same rules. Why is there a need for distinguishing scholarly academic works from works meant for the entertainment industry? Arguments for separating the two categories of works are presented below:

- Scholarly works are cumulative. Each work in essence is just a link in the scholarship continuum. The edifice of scientific disciplines is built on the foundations laid by generations of scientists over centuries. It should to be remembered that when the Statute of Queen Anne was enacted, it was clearly meant for literary works and not scientific works. The act of using information and creating information are so closely intertwined, it is almost impossible to separate the two. Academics claim "fair use" for using information. Then is it fair to claim copyright for the act of creating information based on earlier work?

- Ideas are not "copyrightable". According to the present copyright laws, it is the representations of ideas that are copyright, and not the ideas themselves. This clearly reflects the fact that copyright laws are specially tuned to an abstract level not meant for scientific/scholarly works (which are essentially focused on communicating ideas rather than expressing ideas). The essence of scholarly communication is the message rather than the language, which is only a conduit for conveyance. A scholarly work is valued for the ideas that it contains rather than the expressions of those ideas. Therefore, copyright laws which confer rights on the expression of an idea are clearly not intended for scholarly works.

- Institutionalisation of, and public funding for, scholarship. Scholarship is an institutional enterprise in most cases. Almost all academic research is carried out within institutional frameworks. Individual researchers are supported by public funds either directly or indirectly. Though intellectual works are created by an individual, it is rather difficult to separate this from the institutional support 
and infrastructure behind the research. This is especially so in increasingly infrastructurebased research activities. Most of the time, researchers are paid for their academic work. The music, movie and other entertainment industries work on a very different structure, and hence perhaps demand the very restrictive and protectionist copyright system that exists today.

- Moral aspects of scholarship should be the central axial principle of scholarly works. Creators are generally more concerned about "paternity" of works than expecting economic returns. Authors are responsible for the validity of their writings and also should protect their moral rights, in terms of acknowledgments and citations. In scholarship, rewards are based on credit and other intellectual dimensions, and should not be economic. In fact the culture of scholarship has evolved such a system of rewards. Current copyright laws distinguish between "fact-based" and fanciful works. Copyright is not applicable for fact-based works. Most academic research is fact-based and not fanciful, and therefore strictly speaking does not come under the provisions of the present copyright laws. It may also be noted that the definition of intellectual property by WIPO given earlier does not explicitly cover "scholarly works" as it defines "creations of the mind: inventions, literary and artistic works, and symbols, names, images, and designs used in commerce [...] which includes literary and artistic works such as novels, poems and plays, films, musical works, artistic works such as drawings, paintings, photographs and sculptures". The economic interests are not the ones to govern scholarship. In fact it is difficult to answer the question of who owns academic research.

- Lack of copyright laws for oral traditions. In oral traditions, before the advent of easy replication afforded by printing technologies, the concept of copyright did not exist. It is the act of "fixing" an idea in a particular medium that brings up the question of copyright. Maybe it is time that we turn around and argue that the digital medium is not a "fixed" medium, and hence we should question the validity of applying the principles of the print paradigm. In the print world ideas were fixed into a medium/container for the purposes of distribution. But today, distribution does not happen in a "fixed mode" but takes place in a fluid state. It is archiving that "fixes" the content and costs more than distribution, particularly for maintenance of the archive. It perhaps makes good sense to evolve an altogether different model for the conceptual system of copyright - one based on the archive model and not the distribution-based business model. Although it appears to be very revolutionary, given the restrictive abilities that the Digital Rights Management (DRM) software can impose, it is worthwhile to consider and revisit copyright laws from a fresh perspective of "archiving" rights rather than "copying" rights. Since the technology exists to make perfect copies that can be easily distributed, and DRM software and other technologies enable the rights holders to restrict the "life" and "use" of digital materials, it is possible to conceptualise a model restricting the archiving/life of a copy of digital material by permitting only those who have rights to archive.

\section{Libraries, archiving and preservation issues in the digital age}

Closely tied to the issues of copyright with respect to digital information is the archiving and preservation of digital resources. Digital materials do not lend themselves easily to some of the provisions of copyright laws, such as "doctrine of first sale". As we move from subscription/ purchase-based models to access/licence-based models, the issue of first sale becomes difficult to formulate and indefinable. E-journals, for instance, can present many controversial issues for libraries related to the ownership and preservation of the digital medium and determination of the roles and responsibilities for maintaining the digital archive. Some very interesting and vexing questions are raised. For example, during the reports from the Association of College and Research Libraries/Scholarly Publishing and Academic Resources Coalition at the American Library Association Meeting in January 2003 (http://library.ucsc.edu/science/ELD/2003/ reports2003.html), the audience was asked "Just why are libraries involved in subscribing to e-journal sites when the e-journals are not residing in the library and are being used largely outside the library?" Libraries now rely on, and spend a lot of money on, digital assets that they neither own nor manage. A joint statement by the International Federation of Library Associations and Institutions (IFLA) and the International Publishers Association clearly states that "while publishers can generally ensure short term archiving of their publications so long as these are economically viable, libraries are best placed to take the responsibility for long term archiving through appropriate arrangements with publishers" (IFLA and IPA, 2002). 
The digital medium itself is deeply mired in legitimate concerns about the technological obsolescence and endurance of the medium. Questions have been raised about the issues of policies and technologies for preservation.

Traditionally the preservation of scholarship has been a function of libraries. In the print paradigm, publishers were not bothered about preservation while libraries took great pains to preserve, and in many academic institutions issues of journals may be bound into volumes and remain accessible for users, via the library archive, long after the journal has ceased publication. In the digital paradigm this function is slowly shifting to the publishers. The issues that compound the fact are the problem of lack of infrastructure and the wherewithal in libraries to undertake preservation and the software required for searching and accessing the archive that is developed at considerable cost by the publishers.

From the libraries' perspective, e-journals that exist only on publishers' servers may be subject to corruption, sabotage, subsequent alteration and selective preservation. Libraries are concerned that publishers, driven by market and profit forces, are not the right agencies to be entrusted with the responsibility of preservation. Apprehensions centre around the perception that publishers may be reluctant to invest and reinvest in archiving older materials once commercial viability diminishes or is lost (Webster, 2002). The issues of mergers, closedowns and take-overs are other matters of contention. Libraries have been the guardians of societal intellectual inheritance, but in the digital age this appears to be changing, especially in respect of e-journals.

Libraries need to advocate and champion the cause of restoring/retaining this traditional responsibility. It is heartening to note that there have been initiatives and efforts in this direction. For instance, the initiative of the National Library of The Netherlands and Elsevier Science (see www.kb.nl/kb/resources/frameset_kb.html?/kb/pr/ pers/pers2002/elsevier-en.html) perhaps addresses the archiving issue to the satisfaction of both the publishing and the library community. This initiative is an example of encouraging publishers to commit to a well-defined preservation policy. In August 2002, the Koninklijke Bibliotheek (KB) of The Netherlands and Elsevier Science signed an agreement whereby KB would become the official digital archive for Elsevier Science's 1,500 journals. This is an interesting development which is worth emulating as it evokes the traditional role of the library in undertaking preservation responsibilities while also asserting the commercial role of the publisher. Such a system potentially provides the assurance and trust required by libraries that the content they are licensing will be retained over time, while at the same time letting publishers exercise and enjoy their commercial rights.

\section{Copyright and theses and dissertations}

Copyright issues related to academic research output in the form of theses and dissertations are very murky. Commercial publishers do not come into play directly, but there are publishing concerns of the creators that can affect copyright aspects. The competing parties are not the scholarly community and publishers, but are within academia. The views expressed in this paper are partly the result of work in developing policy frameworks for creating a national archive in India of theses and dissertations in the Vidyanidhi Digital Library Project (www.vidyanidhi.org.in).

Most of the copyright issues related to scholarly communication apply equally to the world of theses and dissertations. Further factors such as those outlined below underscore the case for separating scholarly works from entertainment in respect of copyright. They include:

- Support by public funds. Doctoral research is almost invariably funded by governments and other such funding agencies, both directly in the form of fellowships as well as indirectly in the form of infrastructure support.

- Collaboration. Theses and dissertations involve collaboration between researchers, academic supervisors and the academic support system in the form of the review and examination of the research.

- Lack of formal publication. Theses and dissertations are unpublished works as they may or may not be published at all and hence almost lost to scholarship, as access would be severely limited. The provisions of compulsory licensing may also be made applicable in order to archive doctoral works digitally.

- Intellectual heritage. Theses and dissertations of research students are part of the intellectual heritage of the academic institution in which the work is undertaken.

- Public defence convention. The tradition of a doctoral student defending the thesis in public implies that doctoral research works should be made publicly accessible.

The Electronic Theses and Dissertations (ETDs) movement the world over (www.theses.org) has raised very pertinent issues with regard to the archiving of and access to this form of literature, 
and fundamental questions regarding who owns doctoral research works have been raised.

Once again, perhaps, certain generic principles outlined above help guide us in gracefully accommodating the concerns of all stakeholders. Libraries are within their limits in digitally archiving and providing access to theses.

\section{Conclusion}

Perhaps the time is ripe for separating the copyright issues for scholarly works from "entertainment" works. The paradigms that govern, or should govern, scholarly works are moral aspects rather than economic aspects. The fundamental distinction of academic research is that it is "fact-based", publicly supported, and is part of the intellectual heritage and should tilt the balance in favour of "public good" concerns rather than private interests, and thus be freed from the copyright quagmire.

\section{References}

Baker and McKenzie (2002), Guide to Regional Intellectual Property Laws for Librarians., National Library Board, Singapore.

Besek, J.M. (2003), Copyright Issues Relevant to the Creation of a Digital Archive: A Preliminary Assessment, Council on Library and Information Resources and Library of Congress, Washington DC, available at: www.clir.org/ pubs/reports/pub112/contents.html

Giavarra, E. (1999), "Copyright, libraries and the digital environment", European Copyright User Platform and Current Awareness Campaign for Librarians (Annex), European Bureau of Library, Information and Documentation Associations, The Hague, available at: http://www.eblida.org/ecup/docs/fi_reannex10.htm

IFLA and IPA (2002), "Preserving the memory of the world in perpetuity: a joint statement on the archiving and preservation of digital information", available at: www.ifla.org/V/press/ifla-ipa02.htm

Webster, D. (2002), The Practical Realities of the New Copyright Laws: A Librarian's Perspective, Association of Research Libraries, New York, NY, available at: www.arl.org/info/frn/ copy/websterMLA02.html 